\title{
On the Security and Stability of Large-scale Wind Power Grid-connected System in Fuxin Grid
}

\author{
Zhang Xu, Shao Tianlong, Li Tianqi \\ Fuxin Power Supply Company of National Grid Liaoning Electric Power Co., Ltd \\ henxue1997@163.com
}

Keywords: Fuxin grid; wind power; centralized grid connection; security and stability

\begin{abstract}
With the construction of northern and western wind power base, large-scale regional wind power grid connection begins to affect power system and several power grid accidents in Fuxin grid resulted in partial off-grid in recent years, causing certain damages on the security and stability of power system. The author takes Fuxin power grid as example to analyze on two problems existing in large-scale wind power centralized grid connection: frequent fluctuations and reactive voltage control, study on the effect of large-scale wind power centralized grid connection on the security and stability of power system and proposes countermeasures and suggestions.
\end{abstract}

\section{Basic Situation of Fuxin Wind Power Base}

Fuxin wind farm are mainly based in the northwest area of Fuxin and eastern Zhangwu. By the end of 2014, there has been a wind power capacity of 1,693,300 kilowatts in operation, among which there are $6220 \mathrm{kV}$ substation, $566 \mathrm{kV}$ substation that delivers power to load centers like Jinzhou and Shenyang by $220 \mathrm{kV}$ tie line. According to Fuxin City Plan, there will be an installed capacity of 16,167,000 kilowatts by 2015, among which 8.117 million $\mathrm{kW}$ are thermal power (increasing 6.3 million kilowatts) and 8.05 million kilowatts are new energy (increasing 6.25 million kilowatts); power generation will be as much as 58.1 billion kwh.

\section{Impact of Off-grid Wind Turbines on the Stability of Grid Frequency}

As the proportion of wind power in Fuxin grid continuously increases, impact of wind power on Fuxin grid has become quite obvious and not ignorable. For example, a $220 \mathrm{kV}$ bus short-circuit accident has once occurred in a $220 \mathrm{kV}$ substation in Fuxin area: in number 1 wind farm (connected to $220 \mathrm{kV}$ bus-bars), three-phase contact line short-circuit occurred due to internal fault and at the same time both sides of the line protected the right action and switches broke smoothly to remove the fault rapidly, making the number 1 wind farm completely off grid and the output immediately reduced to zero.

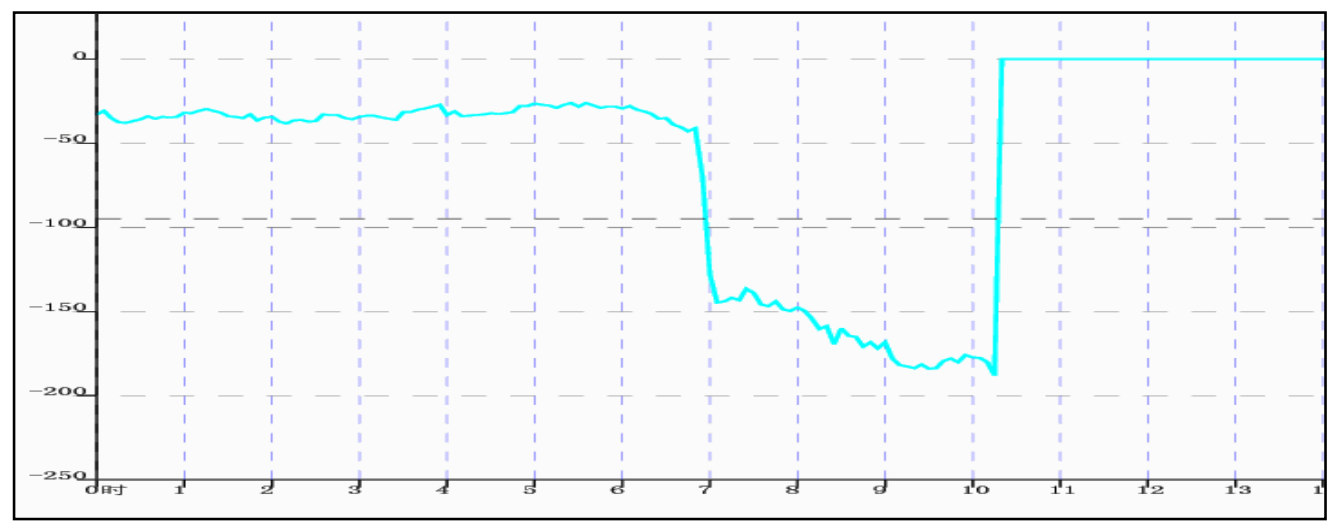

Figure 1. output curve of Number 1 wind farm (substation side)

It is an end substation in Fuxin area where the grid structure is relatively weak and the system voltage can be significantly affected by faults. Meanwhile, the substation is the source for two 220 $\mathrm{kV}$ side grid-connected wind farms and two $66 \mathrm{kV}$ side grid-connected wind farms. 
The short-circuit fault caused $220 \mathrm{kV}$ system voltage of the substation to drop under the rated value and then number 1 wind $220 \mathrm{kV}$ turbine should enter low voltage ride through stage, continuing to run and provide reactive current for the system. Within 200ms, the fault line was cut down and the system voltage recovered to normal; according to the LVRT requirement, the fan should resume normal operation and adjust the output to the original value before the fault.

According to the actual data of number 1 wind farm, the system voltage dropped and recovered to the normal value; the fan failed to finish the "ride through" of low voltage completely; among the 143 fans in operation in number 1 wind farm, 71 wind turbines dropped off the grid due to reduced voltage and the rate of successful ride through of low voltage was only $49.70 \%$.

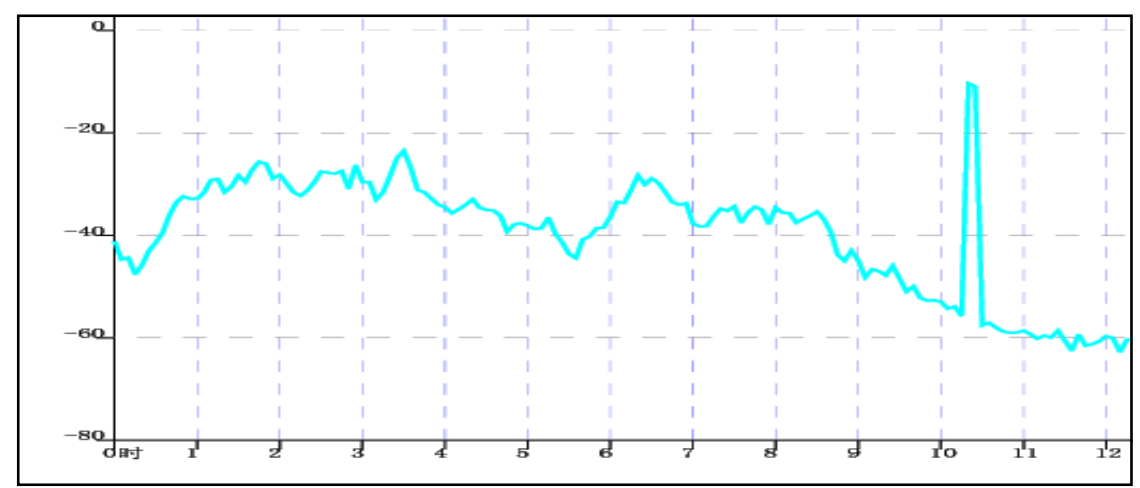

Figure 2. output curve of number 2 wind farm (Zhangwu substation side)

Like $220 \mathrm{kV}$ system, the voltage of $66 \mathrm{kV}$ system of Zhangwu substation was also greatly affected so that Guben wind farm was also taken off the grid. According to the operation data and output curve of number 2 wind farm, among the 52 wind turbines in operation, 37 wind power generators were taken off the grid due to voltage change when low voltage ride through and the success rate of low voltage ride through was $18.57 \%$. The average success rate of low voltage ride through of both number 1 and 2 wind farms is $39.87 \%$.

By the end of 2012, total installed capacity of the grid system in Liaoning was 38,070,100 kilowatts and the annual load of Northwest power grid was 42 million kilowatts, with the minimum load of 31 million kilowatts. Under this condition, Fuxin system would loss 106,100 kilowatts output caused by off-grid accidents. Theoretically, the equation is:

$$
-\Delta P_{L} / \Delta f=K_{G}+K_{L}=K_{S} \quad \text { (1) } K_{L}=\frac{K_{L} * P_{L N}}{f_{N}} \text { 。 }
$$

Per unit value of power adjustment voltage of Liaoning system comprehensive load is 1.5 and per unit value of power adjustment voltage of the generator is set as 3.71 by experience. Based on the above equation, output loss caused by this wind power fault is 106,100 kilowatts and the transient frequency is up to $49.9672 \mathrm{~Hz}$, which is under the protection starting value and the low voltage load-shedding device won't start up; therefore the system will gradually recover to normal operating status and no large area of load shedding will occur.

With the development of wind power and gradual increase of installed capacity, large area of load shedding in wind turbines will exert more impact on system frequency and the long term target of installed capacity of wind turbines in Fuxin area is 5 million kilowatts. Then the permanent fault of lines will lead to reduced grid voltage; considering the success rate of low voltage ride through of wind turbines, accidents will affect the system frequency; take the worst condition as example, success rate of low voltage ride through is set as $39.87 \%$ as above, output loss is 3.26 million kwh, and the minimum system load is set as 31 million $\mathrm{kW}$. According to the results of calculation, the system transient frequency is affected seriously at this time and can be reduced to $48.9908 \mathrm{~Hz}$; it is under the low voltage load-shedding value and partial low voltage load-shedding devices starts up and cut off load lines in turn, which will lead to load loss and even large area of blackout accidents when it is serious, threatening the stability of grid economy. Under large loads, the frequency will be better than under little loads, but it can occasionally lead to low frequency load-shedding caused by reduced frequency after large area of wind turbines off-grid. 
Based on the above analysis, it can be concluded that off-grid phenomenon due to failures in low voltage ride through of turbines caused by permanent fault in lines and others will cause damages on and reduce system frequency to $48.9908 \mathrm{~Hz}$ when it is severe, which will activate the low frequency load-shedding device and lead to power failure and load loss. Meanwhile, it will expand the line fault scale and threaten security of the system, blocking the stable operation of grid.

\section{Impact of Wind Power Grid Connection on the Voltage Stability in Fuxin Area}

Due to the volatility and uncertainty of wind power, the access load of wind farm can fluctuates greatly. Some of the wind farms still use capacitors as the reactive power compensation equipment. Even the SVG equipment, if added, often takes zero reactive exchange of wind farm exports or bus constant voltage as the control target, resulting in quickly and frequently reactive transformation changes in the grid connection points. Such end substations as Zhangwu 220 kilovolt substation in Fuxin area have more obvious impact on stability of voltage.

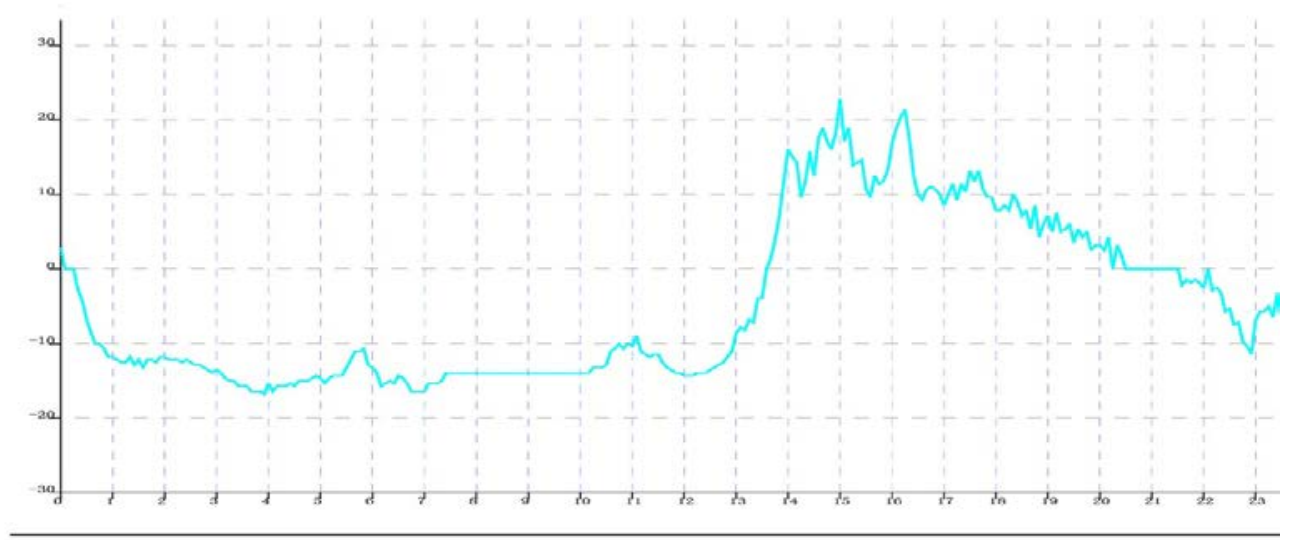

Figure 3. output curve of Zhangbei wind farms

As shown in the above figure 3, when the wind speed increases suddenly, large numbers of fans (then about 200 fans start up in Zhangbei wind farm) will be connected to the grid simultaneously and reaches to rated power quickly; during the process fans absorb large amounts of reactive power from the grid and then are compensated by reactive power compensation devices; the voltage recovers to the original level and causes great fluctuations in voltage of the connection point during the process.

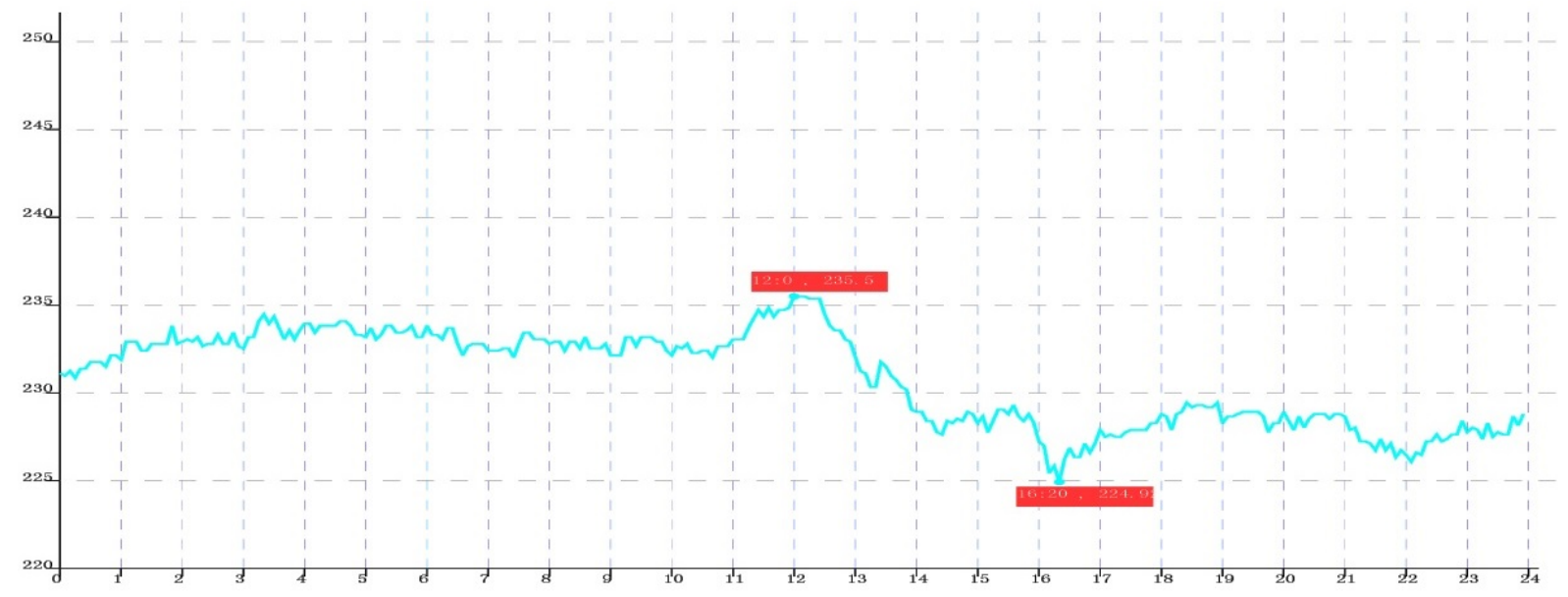

Figure 4. 220 kilovolt bus voltage in Zhangwu 220 kilovolt substation

There is no connection line between Zhangwu substation and other 220 kilovolt substations in Fuxin area and thus the inter-system reactive power support is insufficient. As shown in the above 
figure 4, during the process of Zhangbei wind farm power increasing from 131 megawatts to 354 megawatts, the primary bus voltage of Zhangwu substation reduces from $234 \mathrm{kV}$ to $224 \mathrm{kV}$ significantly. The stability of Zhangwu substation is affected greatly by wind farm and if the grid-connected capacity continues to increase, the stability problem in Zhangwu substation will become more prominent.

\section{Suggestions of the Impact of Grid-connected Wind Power on Stability of the Grid}

\section{Suggestions of the impact of grid-connected wind power on stability of the frequency}

The first is to control the total grid-connected capacity of the grid-connected wind farms, especially the wind farm capacity of end substations that are connected to the grid. Meanwhile, check on the stability of grid regularly and equip additional protection devices in the connection point if necessary to cut off faults quickly and prevent faults to expand or cut off more turbines in wind farms. The second is to ensure that turbines of newly grid-connected wind farms should be capable of low voltage ride through and reduce the grid-connected capacity when faults occur in the grid.

Suggestions of the impact of grid-connected wind power on stability of the voltage

1) Obtain reactive balance on the spot and realize zero reactive flow in the connection point of wind farms

Wind farm reactive power compensation on the spot should be the basis to solve the voltage fluctuation problem of wind farms. According to the "hierarchical and regional balance on the spot" principle of reactive power compensation, it is desirable to set stratified compensation between the exports of wind farm turbines and wind farm connection point, ensuring "zero flow" of reactive power in the connection points of wind farms in the substation under normal conditions. The specific solution is as following:

Proper reactive power compensation equipment should be set in the exports, $35 \mathrm{kV}$ bus pool and high voltage side of the main transformer. It is not desirable to use capacitor switching to compensate but SVG devices that can track and do adjustments quickly. Meanwhile, all these devices should be capable of cooperating with the corresponding scheduling mechanism AVC system: regulate flexibly the reactive power in the wind farm on the basis of reactive power "zero flow" and provide certain reactive power support for the grid and guarantee the low voltage ride through ability of wind farms. With the rapid construction of wind farm, wind farms unable to guarantee reactive power compensation capacity and compensation speed should be required and urged to carry out improvement measures as soon as possible.

2) Carrying out rapid reactive power adjustments with large capacity in the centralized connection points

Besides ensuring that all grid-connected wind farms are able to meet the reactive power need in daily power generation (sufficient SVG devices are suggested to be installed in grid-connected wind farms), dramatic wind speed changes under extremely bad weather should also be taken into consideration; when wind farms with large capacity are connected or cut off the grid suddenly, stability of voltage in booster stations should be first ensured in wind farm reactive power compensation equipment, but is less helpful for the grid.

Therefore, the central point of electricity delivery in wind farms should be taken into consideration. For example, SVG device is equipped beside the 66 kilovolt bus in Zhangwu 220 kilovolt substation to ensure rapid reactive power compensation when accidents occur during wind power delivery, so as to ensure the stability of grid voltage and prevent short voltage fluctuations from causing voltage exceeding and even voltage instability.

\section{Conclusion}

Electric source, grid and overall electricity market planning should be enhanced first in Large-scale wind power grid connection to mitigate the contradiction between large-scale wind power adjustment peak, delivering capability and consumption and ensure the basic condition for 
stable operation of electricity system; the second is to impose a reasonable increase in the technical standards of large-scale wind power base construction so as to enable wind farms with active power control, reactive power control and low voltage ride through capability, ease the impact of large-scale centralized grid-connected wind power on the security and stability of electricity system and promote the sustainable, stable and healthy development of large-scale wind power bases.

\section{References}

[1] Sun Tao, Wang Weisheng, Dai Huizhu, Yang Yihan. Voltage Fluctuation in Wind Power and Flicker Grid Technology, Vol. 24, 12, 2003.12

[2] Wang Xiaorong, Wang Weisheng, Dai Huizhu. Development and Prospects of wind power in China, Vol. 37, No. 1, January 2004

[3] Hu Qiying. New Development Trend of Wind Power in Germany, Solar Power, 20041

[4] Guo Qinglai. On the closed-loop control of phased reactive power voltage in electricity system, Beijing: Tsinghua University, 2005.

[5] Yang Hua, Liang Haifeng, Li Gengyin. Voltage coordination and control measures of wind farms in doubly-fed induction generator, Automation of Power System, 2010, 35 (2): 112-126. 